http://jmscr.igmpublication.org/home/ ISSN (e)-2347-176x ISSN (p) 2455-0450

crossref DOI: https://dx.doi.org/10.18535/jmscr/v8i11.40

Journal Of Medical Science And Clinical Research

\title{
Evaluation of Postoperative Pyrexia within 48 Hours of Elective Surgery in General Surgical Ward of Rajah Muthiah Medical College and Hospital
}

\author{
Authors \\ Dr Guru Praveen ${ }^{1}$, Dr N.Junior Sundresh ${ }^{2}$, Dr D.Gopikrishna ${ }^{3 *}$, Dr R.Logesh Kumar ${ }^{4}$, \\ Dr P.Vigneshwaran ${ }^{5}$ \\ ${ }^{1,4,5}$ Post Graduate, Dept of General Surgery, Rajah Muthiah Medical College and Hospital, Annamalai \\ Nagar, Chidambaram, India, 608002 \\ ${ }^{2}$ Professor, Dept of General Surgery, Rajah Muthiah Medical College and Hospital, Annamalai Nagar, \\ Chidambaram, India, 608002 \\ ${ }^{3}$ Associate Professor, Dept of General Surgery, Rajah Muthiah Medical College and Hospital, Annamalai \\ Nagar, Chidambaram, India, 608002 \\ *Corresponding Author \\ Dr D.Gopikrishna
}

Associate Professor, Dept of General Surgery, Rajah Muthiah Medical College and Hospital, Annamalai

Nagar, Chidambaram, India, 608002

\begin{abstract}
Background: Fever or pyrexia is a disorder of body's thermoregulation. Fever has been reported in $40 \%$ of patients after major surgery which may arise from either infectious or non-infectious causes. It may be an early presentation of a potentially fatal problem, or part of a more benign process, such as atelactasis or drug fever, infectious and non infectious causes. This study is based on the early evaluation of pyrexia of a post operative patient, identifying the cause reducing the complications
\end{abstract}

Aim and Objectives: To evaluate causes of postoperative pyrexia within 48 hours of elective surgery in a post operative surgical ward

Methods: This is a descriptive prospective study of 100 cases with operative pyrexia in post operative wards of Rajah Muthiah Medical College from 2018 to 2020. Elective surgical patients who had temperature of $38 \mathrm{C}$ or more within $48 \mathrm{hrs}$ was analyzed Causes of postoperative fever evaluated on the basis of history, clinical examination and with the aid of investigations. The data supporting this study includes kind of surgery performed, clinical symptoms \& signs and specific investigations during postoperative period.

Results: Most common cause of fever within 48 hours was atelactasis in 55\%. Other causes were Thirty six percent patients were diagnosed as cases of unexplained fever as clinical findings and investigations including chest radiographs did not show any abnormality. Clinical examination of 03 cases showed pain, redness and swelling at cannula site. On clinical correlation they were diagnosed as case of phlebitis. Urinary tract infection occurred in six patients.

Conclusion: In this study non infectious causes shows more incidence of post operative pyrexia. In this study Atlectasis is the most common cause within $48 \mathrm{hrs}$ of post operative pyrexia, further studies have to done to rule out more causes and for more time period with more number of cases.

Keywords: Post-operative, fever, pyrexia, atelactasis. 


\section{Introduction}

Fever or pyrexia is a disorder of body's thermoregulation. As studies shows more than 40 percentage of people will get post operative fever after surgical procedures. The cause my varied from non infectious to infectious causes. This post operative pyrexia have to be evaluated thoroughly to exclude the fatal causes to reduce mortality. Fever-associated cytokines, such as interleukin IL1, IL-6, tumor necrosis factor (TNF)-alpha and interferon (IFN)-gamma are produced in the body as a tissue response to injury. There is some evidence that IL-6 is the cytokine most closely associated with postoperative fever. in the post operative period most of the times pyrexia is self limiting. However the role of surgeon or physician with expert opinion is to exclude the major causes of post operative pyrexia and thus saving patients life. The patient's history, a targeted physical examination and further studies supporting the diagnosis are needed to identify the causes of post operative pyrexia and this study shows the early evaluation of pyrexia with in $48 \mathrm{hrs}$ before a patient suffers from complications.

\section{Material and Methods}

This is a descriptive prospective study of 100 cases with post operative pyrexia in post operative wards of Rajah Muthiah Medical College from 2018 to 2020. Elective surgical patients who had temperature of $38 \mathrm{C}$ or more within $48 \mathrm{hrs}$ was analyzed the fever within $48 \mathrm{hrs}$ post operatively evaluated on the basis of history, clinical examination and with the aid of investigations. The data supporting this study includes kind of surgery performed, clinical symptoms $\&$ signs and specific investigations during postoperative period. Evaluation was based on history, targeted clinical examination and specific investigations. Different variables of this study were age, temperature, respiratory rate and total leukocyte count. Categorical data obtained from the study included gender, clinical findings (cough, shortness of breath, decreased breath sounds or crepitations), chest radiographs. All the information was analyzed using SPSS version 16 to calculate means and standard deviation for quantitative variables and frequencies for the categorical data.

\section{Results}

This is a Prospective study of 100cases of postoperative patients who had postoperative pyrexia within 48 hours of elective surgery was carried out. Commonly used anesthesia in elective surgery was general anesthesia.

There were $64 \%$ patients who underwent general anesthesia while $22 \%$ surgeries were done under local anesthesia and $14 \%$ under spinal anesthesia.

Table 1: Type of anaesthesia and operative procedure

\begin{tabular}{|l|c|c|c|}
\hline Operative procedure & General anesthesia & Spinal anastheia & Local anasthesia \\
\hline Anorectal procedure & 03 & 02 & 00 \\
\hline Cholecystectomy & 19 & 00 & 00 \\
\hline Thyroid surgery & 17 & 00 & 00 \\
\hline Inguinal hernia & 02 & 12 & 14 \\
\hline Colorectal malignancies & 08 & 00 & 00 \\
\hline Ventral hernia & 03 & 00 & 00 \\
\hline Breast surgery & 12 & 00 & 08 \\
\hline Total & 64 & 14 & 22 \\
\hline
\end{tabular}


Table 2: Etiology of fever and distribution among various surgery

\begin{tabular}{|l|c|c|c|c|c|c|c|c|}
\hline Causes & $\begin{array}{c}\text { Anorectal } \\
\text { surgery }\end{array}$ & $\begin{array}{c}\text { Breast } \\
\text { surgery }\end{array}$ & cholecystectomy & $\begin{array}{c}\text { Thyroid } \\
\text { surgery }\end{array}$ & $\begin{array}{c}\text { Inguinal } \\
\text { hernia }\end{array}$ & $\begin{array}{c}\text { Ventral } \\
\text { hernia }\end{array}$ & $\begin{array}{c}\text { Colorectal } \\
\text { malignancies }\end{array}$ & total \\
\hline Atelectasis & 00 & 18 & 17 & 12 & 2 & 07 & 01 & 55 \\
\hline $\begin{array}{l}\text { Unexplained } \\
\text { fever }\end{array}$ & 03 & 09 & 05 & 02 & 13 & 00 & 03 & 36 \\
\hline $\begin{array}{l}\text { Urinary } \\
\text { tract } \\
\text { infections }\end{array}$ & 02 & 02 & 01 & 01 & 03 & 00 & 00 & 06 \\
\hline Phlebitis & 00 & 00 & 01 & 00 & 01 & 01 & 00 & 03 \\
\hline
\end{tabular}

Most common cause of fever within 48 hours was atelactasis in $55 \%$. Other causes were unexplained fever in $36 \%$ and Thirty six percent patients were diagnosed as cases of unexplained fever as clinical findings and investigations including chest radiographs did not show any abnormality. Clinical examination of 03 cases showed pain, redness and swelling at cannula site. On clinical correlation they were diagnosed as case of phlebitis. Urinary tract infection occurred in six patients

\section{Discussion}

Fever is one of the most common problems faced in postoperative period. fever increases morbidity of the patient Hence its evaluation is of utmost importance. There is an indirect relationship of female gender with pulmonary complications i.e., atelactasis because of more commonly performed upper abdominal and breast surgeries in them. In this study, fever in $55 \%$ of patients was because of pulmonary atelactasis. It is reported in the literature that upper abdominal and thoracic surgery is the risk factor for the development of pulmonary atelactasis. In our study, majority of the patients who suffered from atelactasis had upper abdominal and thoracic surgery (Breast surgery $32 \%$, Cholecystectomy 30\%). It has been concluded from other studies that upper abdominal surgery (e.g. cholecystectomy) general anesthesia and inadequate pain control are the specific risk factors of atelactasis. In our study, it was observed that lower abdominal procedures were mostly not associated with the development of chest complications eg (anorectal and hernia repairs). Similarly, less incidence of pulmonary complications seen in procedure done under spinal and local anesthesia when comparing with general anesthesia.

3 percent patients were diagnosed as cases of phlebitis.Thirty six percent patients were labeled to have unexplained fever. Clinical examination aninvestigations were unremarkable. Majority of the cases observed was of inguinal hernia repair $(18 \%) \&$ breast surgery (8\%). Anesthesia had no direct relationship with it. Most of them were young and recovered spontaneously. It has been reported that this transient, self resolving fever is because of tissue trauma. Tissue response causes release of cytokines like il 6 which stimulate thermoregulatory system to induce fever. The tissue damage leads to release of IL 6 which acts like a pyrogen and causes postoperative pyrexia also.

\section{Conclusion}

In conclusion early postoperative fever occurs in wide range of post operative patients. Patients with postoperative fever within $48 \mathrm{hrs}$ should be evaluated to identify the sole cause but non infectious causes are more prone to cause pyrexia with $48 \mathrm{hrs}$ of time. In the post operative period most of the times pyrexia is self limiting. However the role of surgeon or physician with expert opinion is to exclude the major causes of post operative pyrexia and thus saving patients life. Our approach in postoperative fever evaluation (based on symptoms and physical examination supported by specific investigations) remained feasible and safe. Common causes are mostly noninfectious, main likely cause is pulmonary atelactasis in post operative patients. No evidence showing empiric antibiotic therapy initiation nor should prophylactic antibiotics be 
extended for prolonged durations. From this study Atlectasis is the most common cause within $48 \mathrm{hrs}$ of post operative pyrexia, further studies have to done to rule out more causes and for more time period with more number of cases.

\section{References}

1. Russell RCG, Williams NS, Bulstrode CJK. Bailey \& Love's Short Practice of Surgery. $27^{\text {th }}$ ed. London. Arnold 2004; 1439.

2. Ghosh, S, Charity, RM, Haidar, SG, Singh, BK. Pyrexia following total knee replacement. Knee 2006; 13: 324.

3. Gerard M,Doherty, SeanJ. Postoperative complications. In: Lawrence W, Gerard M. Current Surgical Diagnosis and Treatment. 11Mc Graw-Hill 2001; 3637.ed. New York

4. E. Patchen Dellinger; Should We Measure Body Temperature for Patients who have recently undergone Surgery? Clinical Infectious Diseases 2005;40:1411-1412.

5. Dinarello CA, Gelfand JA. Fever and hyperthermia. In: Harrison's principles of internal medicine. $16^{\text {th }}$ ed. McGraw Hill: 2005.p.104-7

6. McAlister, FA, Bertsch, K,Man, J, et al. Incidence of and risk factors for pulmonary complications after nonthoracic surgery. AmJ Respir Crit Care Med 2005; 171:51

7. Wylieand Churchill-Davidson's-A Practice of Anaesthesia. $7^{\text {th }}$ ed. London: Arnold 2003.

8. TusmanG, Bohm SH, Vazquezde Anda GF, do Campo JL, Lachmann B. 'Alveolar recruitment strategy' improves arterial oxygenation during general anaesthesia. Br J Anaesth 1999; 82:8-13.
9. Sandham, JD, Hull, RD, Brant, RF, et al. A randomized, controlled trial of the use of pulmonary- artery catheters in highrisk surgical patients. $\mathrm{N}$ Engl $\mathrm{J}$ Med 2003;348:5. 